\title{
DESIGN AND ANALYSIS OF AN AERODYNAMIC DOWNFORCE PACKAGE FOR A FORMULA STUDENT RACE CAR
}

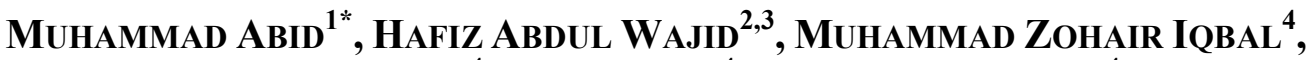 \\ SHAYAN NAJAM ${ }^{4}$, Ali ARSHAD ${ }^{4}$ AND AMMAD AHMAD ${ }^{4}$ \\ ${ }^{1}$ Interdisciplinary Research Center, COMSATS Institute of Information Technology, \\ Wah Cantt, Pakistan. \\ ${ }^{2}$ Department of Mathematics, COMSATS Institute of Information Technology, \\ Lahore, Pakistan. \\ ${ }^{3}$ Department of Electrical Engineering, Islamic University of Madinah, \\ Kingdom of Saudi Arabia. \\ ${ }^{4}$ Faculty of Mechanical Engineering, \\ GIK Institute of Engineering Sciences and Technology, Topi, Pakistan. \\ *Corresponding author:drabid@ciitwah.edu.pk \\ (Received: $28^{\text {th }}$ April 2016; Accepted: $13^{\text {th }}$ Nov. 2017; Published on-line: $1^{\text {st }}$ December 2017)
}

\begin{abstract}
This paper presents design of aerodynamic downforce generating devices (front wing, rear wing and diffuser) to enhance the performance of the Formula Student Race Car using numerical and experimental studies. Numerical results using computational fluid dynamics (CFD) studies were primarily validated with the experimental results performed in the wind tunnel. It was concluded that the use of a downforce package can enhance the performance of the vehicle in the competition.
\end{abstract}

ABSTRAK: Kertas kerja ini mengkaji tentang reka bentuk alatan yang menjana aerodinamik downforce (sayap depan, sayap belakang dan difuser) bagi meningkatkan prestasi Kereta Lumba Formula Pelajar mengguna pakai kaedah numerikal dan eksperimentasi. Keputusan kaedah numerikal menerusi pengiraan dinamik bendalir (CFD) telah di bandingkan dengan keputusan eksperimen melalui terowong angin. Kajian mendapati dengan mengguna pakej downforce boleh meningkatkan prestasi kenderaan dalam perlumbaan kereta.

KEYWORDS: formula; SAE; vehicle aerodynamics; downforce; front wing;rear wing; diffuser

\section{INTRODUCTION}

Formula SAE is an international collegiate design competition organized by the Society of Automotive Engineers (SAE) International and held at various venues around the globe in collaboration with the respective local automotive societies. University students are required to design, fabricate and market a single seat race car, which has to undergo series of rigorous tests, designed to measure its engineering performance to its limits.

Multiple element wings are widely used in motorsport and aviation industry to generate higher coefficient of lift $\left(C_{L}\right)$ than using a single airfoil wing. Since the available areas to install these wings are restricted and regulated on a racing car, but still many formula 1 teams even use 6 to 7 elements on the front wing alone [1]. The design of the 
multiple element wings is very complex due to a number of parameters. For a given set of elements, the region of interest is particularly the area where the flow leaves the first element and moves to the second element. The design parameters include airfoil profiles, chord length, angle of attack, slot gap and overlap (Fig. 1).

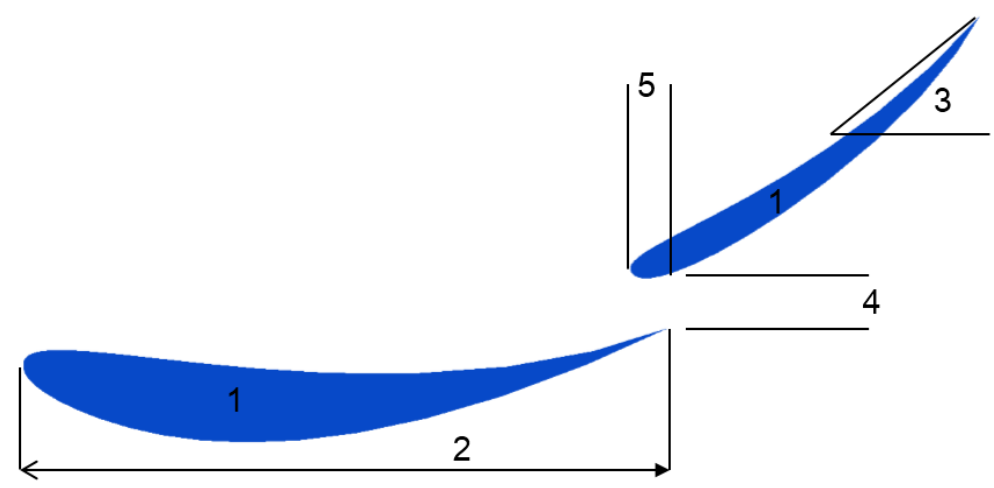

Fig. 1: Multiple element wing schematic: (1) airfoil profiles, (2) chord length, (3) angle of attack, (4) slot gap, (5) overlap.

A number of main element profiles were shortlisted using visual comparison of superimposed airfoils; including flat bottom, high lift, and high cambered and complex shapes. The chord length of the main element was kept constant in each run at $0.3 \mathrm{~m}$ as with this characteristic length, the Reynolds Number stays in the same regime as with the actual dimensions. The angle of attack of main element was also kept constant at 0 degree. Tests were initially performed on single elements alone to find their independent coefficients of lift and drag. The trailing edge exit angles were determined using ProEngineer software [2]. The second element was kept the same throughout all the experiments in the first phase. Eppler 385 airfoil [3] was selected in this case as it exhibits only $8 \%$ thickness with respect to its chord length and has a desirable camber. Chord length of the second element was kept constant at $0.15 \mathrm{~m}$ to satisfy the chord ratio of $2: 1$ between the main and the second element. The slot gap, overlap and angle of attack with respect to the main foil were kept as variable parameters which were then controlled during optimization using ANSYS CFX software [4].

As shortlisting of the second element profiles was done on the basis of observation, therefore main airfoils that were selected previously were kept constant. The first element was selected as BE 122-155 [3] as it produced the highest $C_{L}$ in Case 1; whereas in Case 2, second element profile was made variable and results were analyzed. The chord ratio was kept variable for this phase of the simulation. The second element chord was kept as a variable parameter while the first element chord length was fixed.

\section{TURBULANCE MODEL SELECTION}

An immediate benefit of the realizable k-epsilon model is that it more accurately predicts the spreading rate of both planar and round jets. It is also likely to provide superior performance for flows involving rotation, boundary layers under strong adverse pressure gradients, separation, and recirculation. Both the realizable and RNG k-epsilon models have shown substantial improvements over the standard k-epsilon model where the flow features include strong streamline curvature, vortices, and rotation. One limitation of the realizable k-epsilon model is that it produces non-physical turbulent viscosities in 
situations when the computational domain contains both rotating and stationary fluid zones (e.g., multiple reference frames, rotating sliding meshes). This is due to the fact that the realizable k-epsilon model includes the effects of mean rotation in the definition of the turbulent viscosity. This extra rotation effect has been tested on single rotating reference frame systems and showed superior behavior over the standard k-epsilon model. However, due to the nature of this modification, its application to multiple reference frame systems should be taken with some caution.

The SST model provides superior performance for wall-bounded boundary layer, free shear and low Reynolds number flows. The SST model accounts for the transport of turbulent shear stress and gives highly accurate predictions of the onset and the amount of flow separation under adverse pressure gradients. SST model is recommended for high accuracy boundary layer simulations. However, its dependency on wall distance makes this model less suitable for free shear flows compared to standard k-epsilon method. Moreover, the SST model requires higher mesh resolution near the wall.

Therefore, the model that we have selected for our CFD simulations was the realizable k-epsilon method.

\section{ANALYSIS}

CFD analysis is performed using ANSYS CFX software [4]. During simulations variable parameters i.e. slot gap, overlap, angle of attack and chord length were defined and target values were achieved. Simulations were performed in a relatively large domain to have minimal wall effects [5].

\subsection{Meshing Sensitivity Analysis and Solution}

Initially for the 2D cases airfoil data was collected from www.airfoiltools.com [1]. These airfoils were then modeled and tested using ANSYS Fluent for mesh sensitivity analysis; however in this study only $3 \mathrm{D}$ validation case for mesh sensitivity analysis is presented and discussed. Instead of airfoil, 3D simulation was performed on the Ahmed Body [2] which depicts a simplified shape of a vehicle and has been tested on various occasions in wind tunnel in the past, hence making it a popular calibration too for many CFD engineers [Figure 2]. The Ahmed Body was modeled using Pro-Engineer software and was exported to Design Modeler for pre mesh. The body was split in half since it is a steady state symmetrical problem. An enclosure was created around the body with the same dimensions as the wind tunnel test section $(1.87 \mathrm{~m} \times 1.4 \mathrm{~m})$. Frozen bodies were added to the geometry. First body occupying a volume slightly larger than the vehicle itself and the other two bodies; one at the bottom and other extending from the back were modeled. These bodies were later used during mesh generation as bodies of influence (zones of user defined maximum element size). These body sizing functions were used to model flow accurately such as regions of high vortices, turbulence and flow separation. The Meshing for this domain was performed using ANSYS Workbench. Various meshes were generated with different settings, all of which were later simulated and the errors from the experimental values were noted. Hence the mesh sensitivity analysis was performed on the Ahmed Body. The three frozen bodies that were introduced in Design Modeler were then used for body sizing. In these regions mesh density is kept constant by specifying the maximum element size in the region hence stopping the growth rate in that area (Fig. 3). Mesh of Ahmed Body along symmetry plane, surface and around are shown in Fig. 4. A total of 5 different meshes were used (Table 1). The solver used for the Ahmed Body analysis was ANSYS Fluent using realizable k-epsilon turbulence model with scalable wall functions; hybrid and coupled schemes for initialization and solution 
respectively. For spatial discretization, second order upwind for momentum, turbulent kinetic energy and turbulent dissipation rate is used.

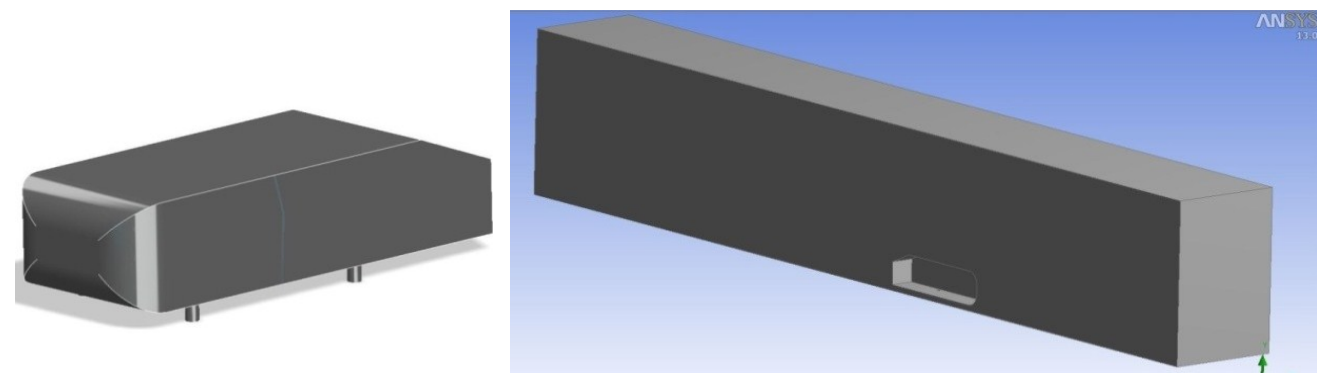

(a)

(b)

Fig. 2: (a) 3D view of Ahmed Body; (b) Ahmed Body modeling.

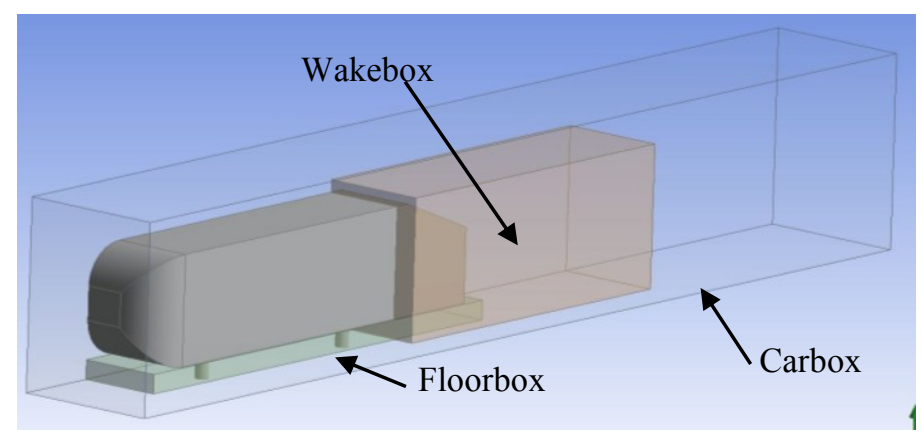

Fig. 3: Model showing test section of Ahmed Body.

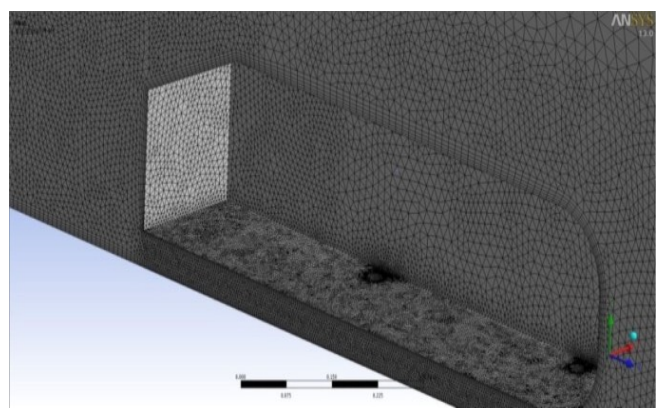

(a)

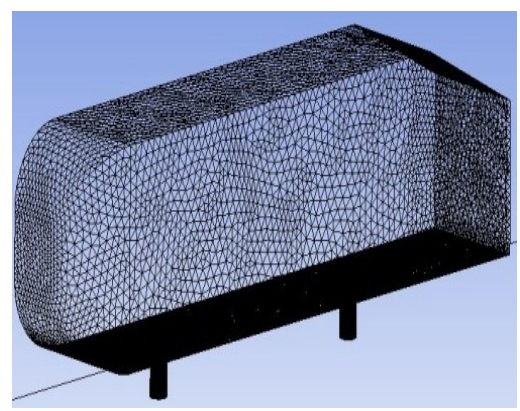

(b)

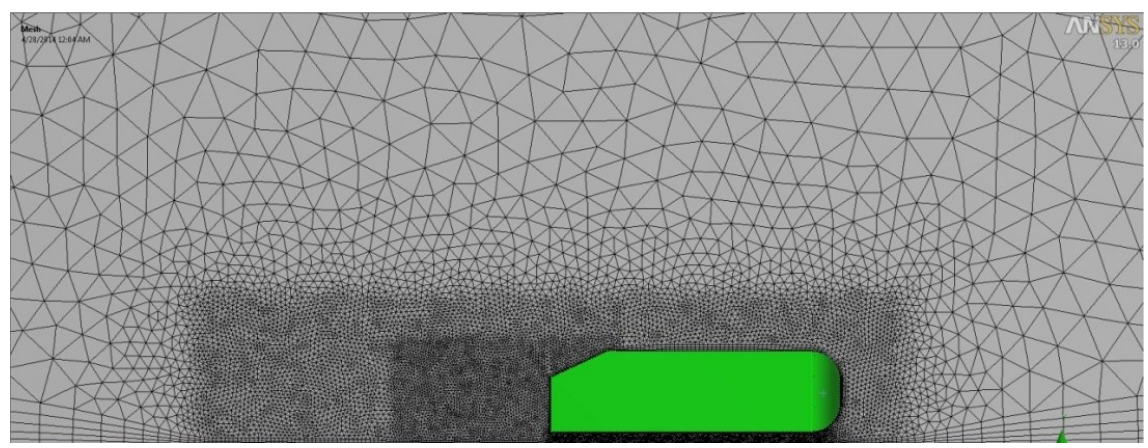

(c)

Fig. 4: Ahmed Body mesh: (a) at symmetry plane; (b) at surface; (c) around. 
Ahmed Body test region and applied boundary conditions are shown in Fig. 5 and mesh sensitivity analysis results are shown in Fig. 6. Numerical results obtained for five different mesh settings were compared with wind tunnel testing conducted at Technical University of Graz, Australia [3,4] and were found in good agreement providing most suitable mesh size during sensitivity analysis. $C_{d}=0.299$ is calculated at wind force $=40$ $\mathrm{m} / \mathrm{s}$; hatch angle $=25$ degree; and Reynolds number $=2.78 \times 10^{6}$. This value of $C_{d}$ is also compared with the analytical values obtained through different CFD simulations in order to validate results. Percentage error in $C_{d}$, solution time, lift and drag coefficients for five simulations with different number of elements, mesh size, force at $40 \mathrm{~m} / \mathrm{s}$ is summarized in Table 1.

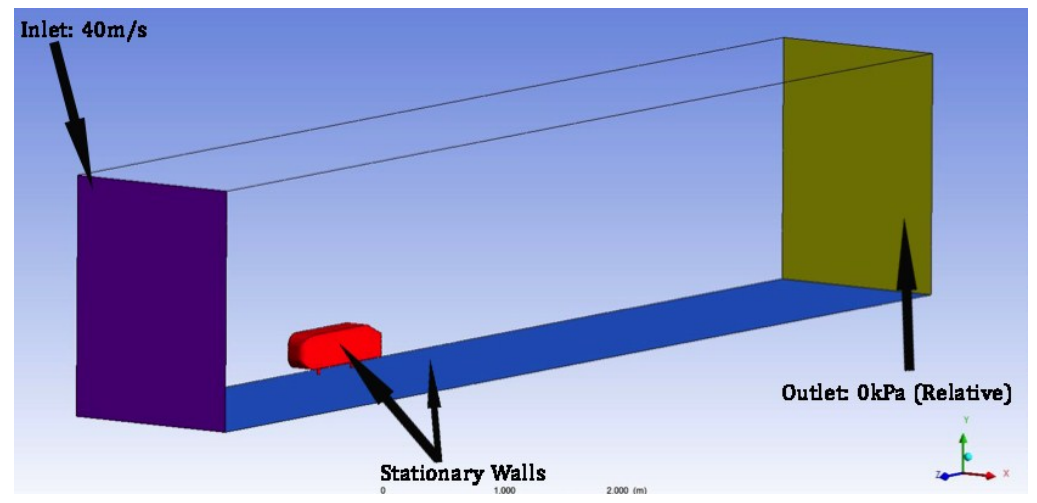

Fig. 5: Ahmed Body in test region.

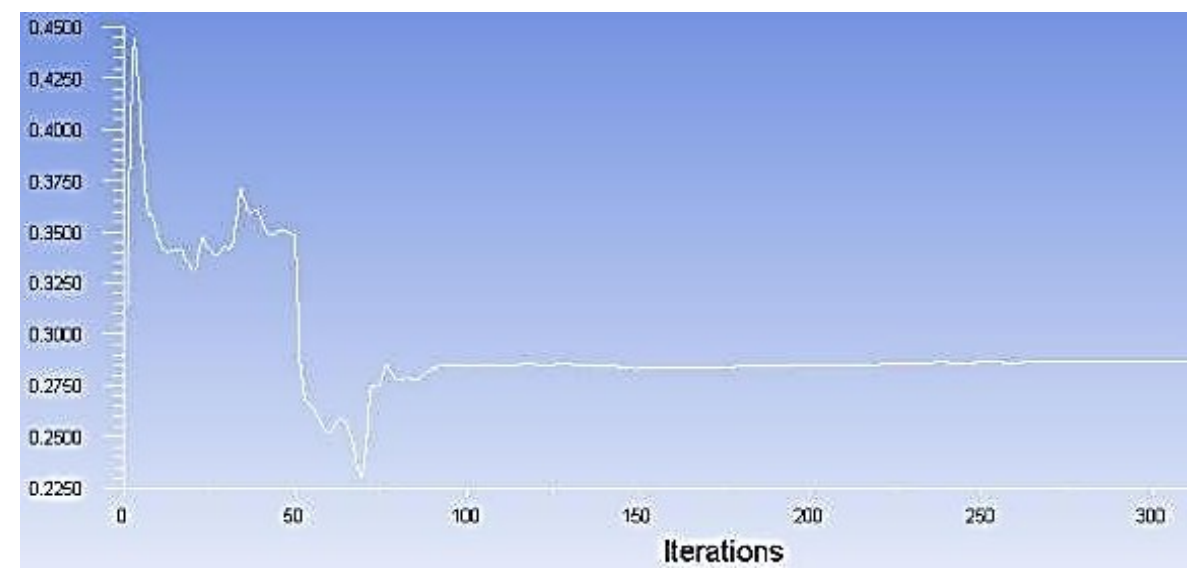

Fig. 6: Solution convergence for $C_{d}$ under different iterations.

Table 1: Results for Ahmed Body mesh sensitivity analysis and validation

\begin{tabular}{|c|c|c|c|c|c|}
\hline $\begin{array}{l}\text { No. of } \\
\text { Elements }\end{array}$ & $\begin{array}{c}\text { Mesh } \\
\text { Settings }\end{array}$ & $\begin{array}{c}\text { Simulation } \\
\text { Time }\end{array}$ & $\begin{array}{l}\text { Forces } \\
\text { at } 40 \mathrm{~m} / \mathrm{s}\end{array}$ & $\begin{array}{c}\text { Coefficients } \\
\text { at } 40 \mathrm{~m} / \mathrm{s}\end{array}$ & $\begin{array}{c}\% \text { Error } \\
\left(C_{d}\right)\end{array}$ \\
\hline 906,000 & Fine & $21 \mathrm{~min}$ & $\begin{array}{l}19.5 \mathrm{~L} \\
17.8 \mathrm{D}\end{array}$ & $\begin{array}{l}\mathrm{C}_{1}=0.346 \\
\mathrm{C}_{\mathrm{d}}=0.316\end{array}$ & 5.3 \\
\hline 988,000 & Fine & $27 \mathrm{~min}$ & $\begin{array}{l}20.96 \mathrm{~L} \\
17.97 \mathrm{D}\end{array}$ & $\begin{array}{l}\mathrm{C}_{1}=0.389 \\
\mathrm{C}_{\mathrm{d}}=0.321\end{array}$ & 6.7 \\
\hline 1.6 million & Medium & $42 \min$ & $\begin{array}{l}22.08 \mathrm{~L} \\
17.60 \mathrm{D}\end{array}$ & $\begin{array}{l}C_{1}^{d}=0.392 \\
C_{d}=0.312\end{array}$ & 4.4 \\
\hline 2.4 million & Medium & $2 \mathrm{hr} 3 \mathrm{~min}$ & $\begin{array}{c}20.35 \mathrm{~L} \\
17.0 \mathrm{D}\end{array}$ & $\begin{array}{l}\mathrm{C}_{\mathrm{d}}=0.302 \\
\mathrm{C}_{1}=0.353\end{array}$ & 0.9 \\
\hline 7.5 million & Medium & $9 \mathrm{hr}$ & $\begin{array}{l}19.37 \mathrm{~L} \\
16.95 \mathrm{D}\end{array}$ & $\begin{array}{l}C_{1}=0.342 \\
C_{d}=0.295\end{array}$ & 0.4 \\
\hline
\end{tabular}




\subsection{Analysis of Aerodynamic Downforce Package}

After detailed modeling and nesh sensitivity analysis and validations, analysis strategy developed is implemented on the aerodynamic downforce package and results are discussed in detail. Two dimensional meshes for multiple element wing analysis are shown in Fig. 7. For Case 1, Maximum $C_{L}=3.63$ was calculated selecting $1^{\text {st }}$ and $2^{\text {nd }}$ element as BE $122-155$ with chord ratio $(C 1 / C 2)$ of 1.42 and $L / D: 21.5$. Where $C 1$ is $1^{\text {st }} C$ hord and $C 2$ is $2^{\text {nd }}$ Chord. For Case 2, Maximum $L / D=54.1$ is calculated selecting $1^{\text {st }}$ element (BE 122$155)$ and $2^{\text {nd }}$ element (E 385) with chord ratio $(C 1 / C 2)$ of 2.5 and $C_{L}=2.83$. Velocity contours for maximum $C_{L}$ arrangement is shown in Fig. 8.
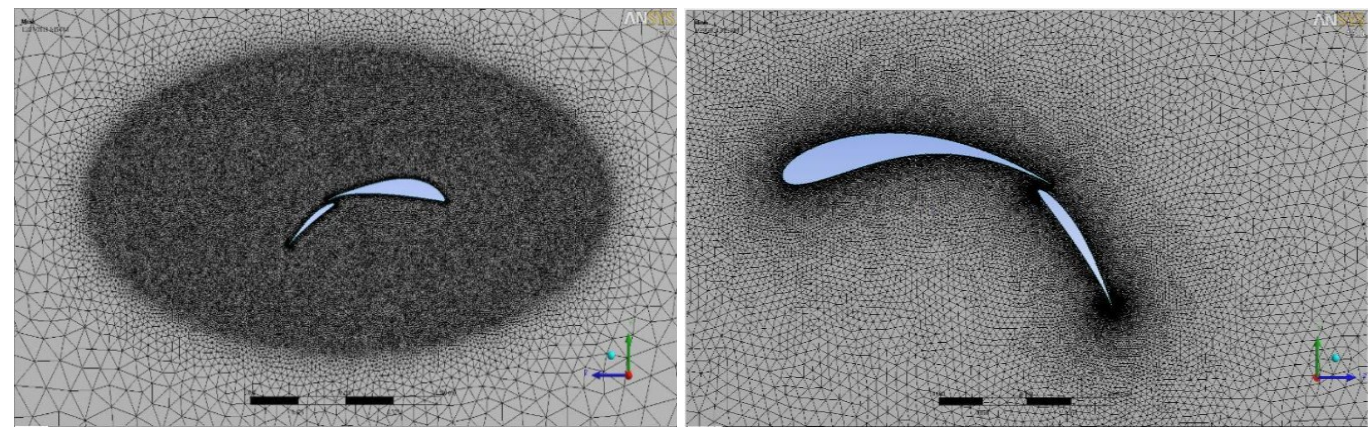

Fig. 7: 2D Mesh used for the simulations.

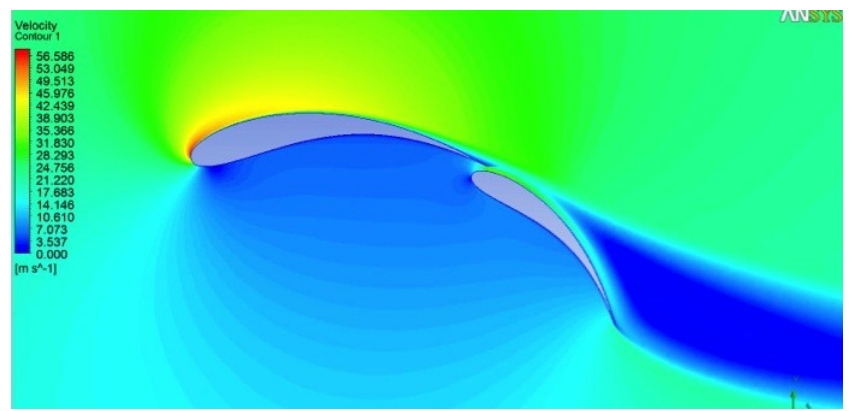

Fig. 8: Velocity contours for maximum $C_{L}$ arrangement.

Analysis is also performed with Gurney flaps or wicker bills (a thin flat plate at the end, oriented at an angle of $90^{\circ}$ to the surface of the trailing edge of the second element) are simple additions to a wing (Fig. 9). This addition of a gurney flap of thickness $(0.05$ C1) resulted in a gain of $5.8 \%$ increase in overall downforce i.e. drastic increase in performance.

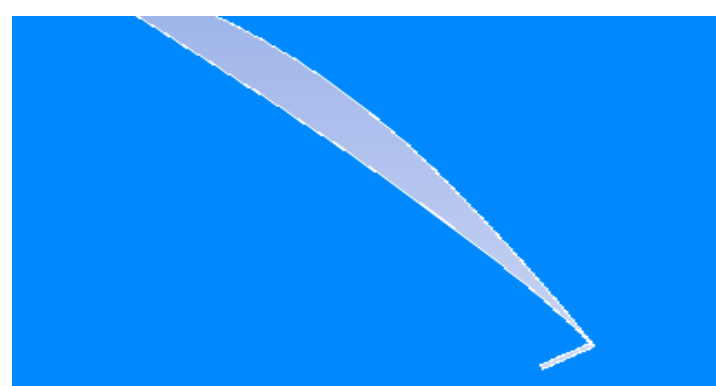

(a)

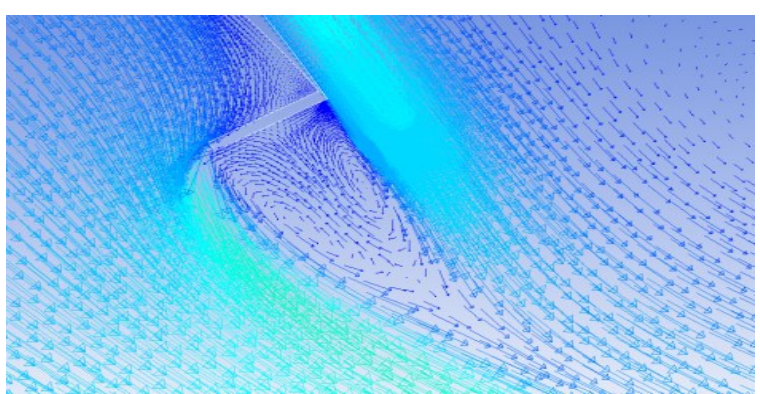

(b)

Fig. 9: (a) Gurney flap on second element; (b) Vectors showing flow pattern across the Gurney. 
Since the front wing is placed close to the moving road surface, a ground proximity analysis was performed on the selected front wing arrangement. Figure 10 shows resultant force variation with ground clearance variation. Due to low available area for the front wing as well as a low aspect ratio, the setup which exhibited the highest $C_{L}$ was selected. Since the front tire sits in the slip stream (wake region) of the front wing, the drag produced by the front wing is compensated by the tire. Whereas for rear wing for free air stream, the highest $L / D$ setup was selected. Numerical results of variation in lift and drag with increasing ground proximity are shown in Fig. 10.

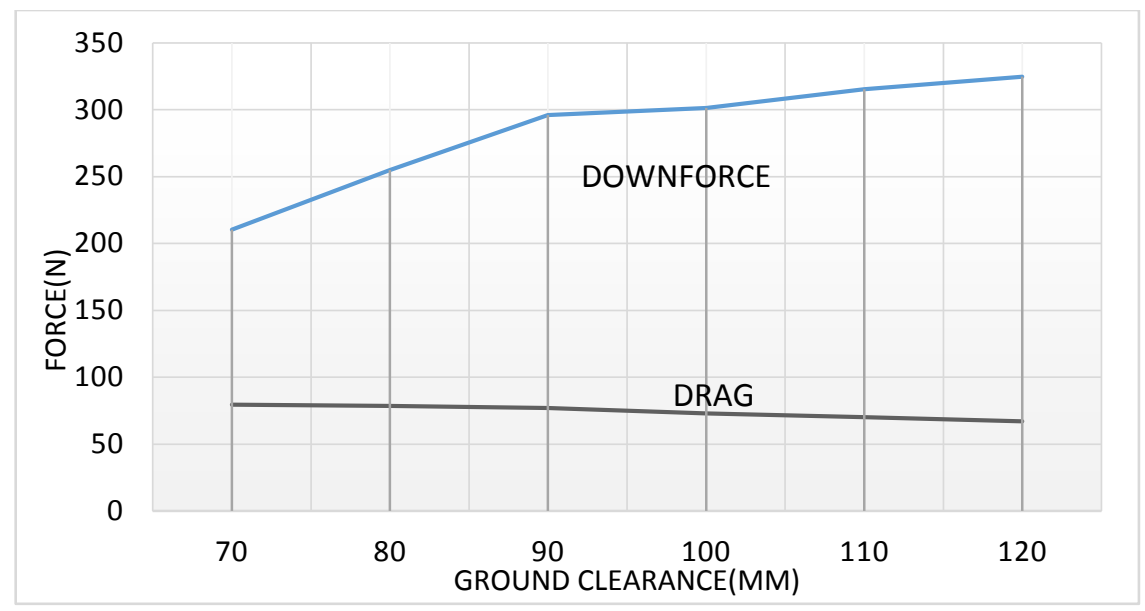

Fig. 10: Lift and drag with increasing ground proximity.

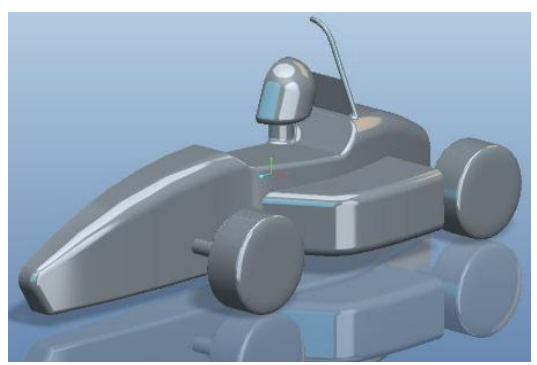

(a)

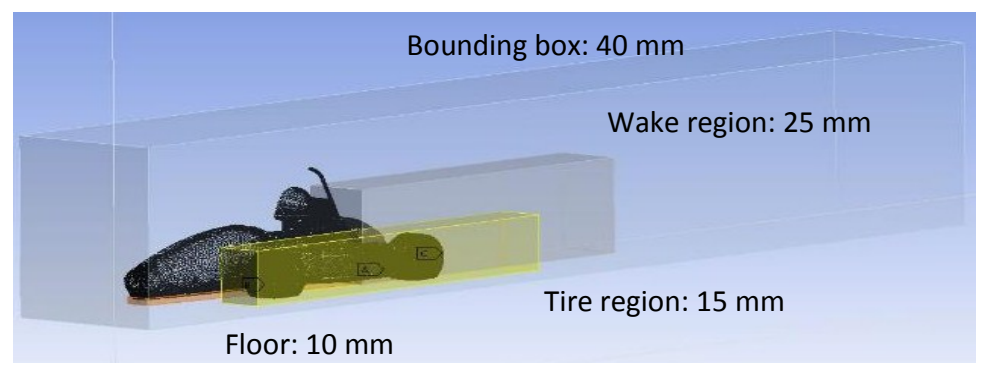

(b)

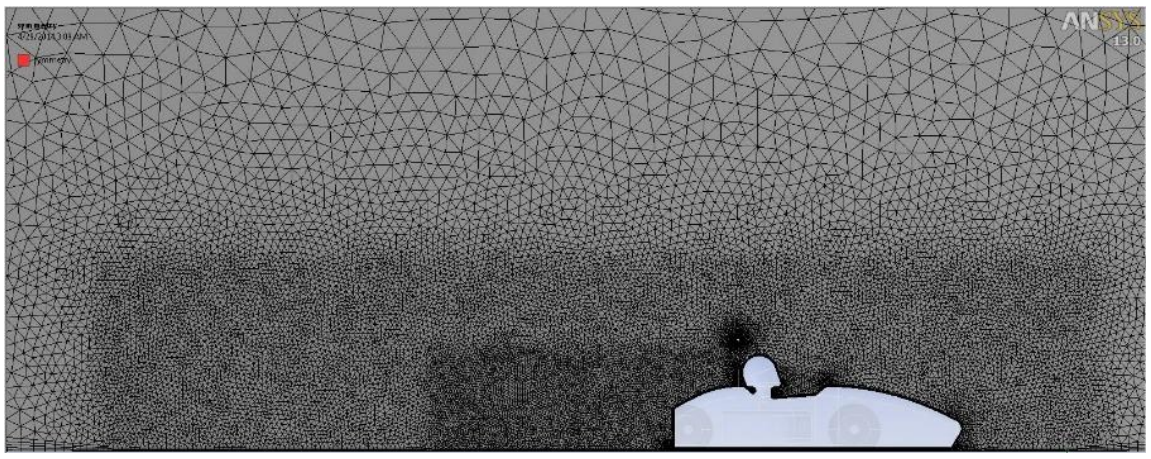

(c)

Fig. 11: (a) Vehicle half model due to symmetry (without the aerodynamic package); (b) body sizing for mesh generation, (c) mesh at symmetry.

\subsection{3-D Analysis}

After finalizing the designs for the wings, the CFD simulations for the entire setup were performed using inlet velocity $=20 \mathrm{~m} / \mathrm{s}$; outlet average relative pressure $=0 \mathrm{~Pa}$, 
rotating wall (tires) at $\omega=82.88 \mathrm{rad} / \mathrm{s}$ and moving wall velocity (ground) $=20 \mathrm{~m} / \mathrm{s}$. First the base vehicle was modeled and tested without any aerodynamic devices. Due to the high complexity required, only a few iterations were performed for the diffuser assembly. The wings were then added to the entire setup and simulated to find out the effective lift and drag at a velocity of $20 \mathrm{~m} / \mathrm{s}$ with frontal area of the vehicle of $0.82 \mathrm{~m}^{2}$. Figure 11a shows vehicle model without aerodynamic package. Figure $11 \mathrm{~b}$ shows the use of body of influence, i.e. body sizing for mesh generation in order to improve the results. Figure 11c shows mesh. Figure 12 shows velocity contours. Downforce, drag and $C_{d}$ are calculated as $11.2 \mathrm{~N}, 109 \mathrm{~N}$ and 0.63 respectively.

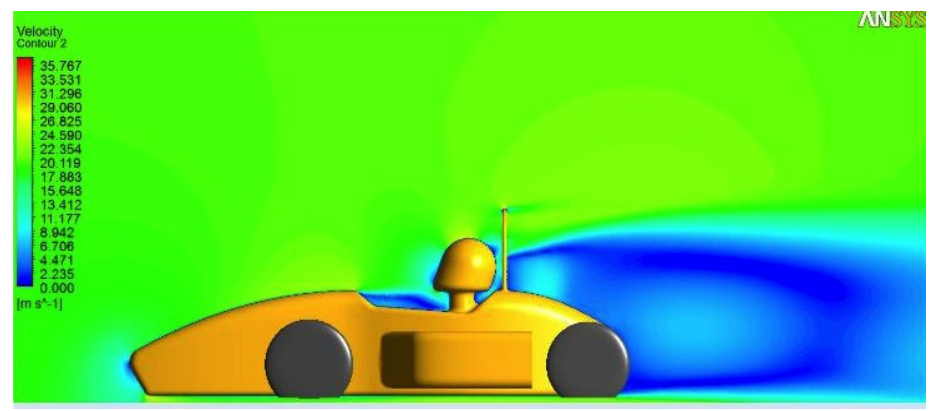

Fig. 12: Velocity contours.

\subsection{Diffuser Design}

A diffuser in an automotive context is a shaped section of the car underbody which improves the car's aerodynamic properties by enhancing the transition between the highvelocity airflow underneath the car and the much slower free stream airflow of the ambient atmosphere. It works by providing a space for the underbody airflow to decelerate and expand (in area, density remains constant at the speeds that cars travel) so that it does not cause excessive flow separation and drag, by providing a degree of "wake infill" or more accurately, pressure recovery. The diffuser itself accelerates the flow in front of it, which helps to generate downforce. For the diffuser to be modeled properly, it is imperative for the entire geometry to be present. The diffuser was designed using racecar vehicle dynamics $[6,7]$ as the guideline. The upsweep angles of $12^{\circ}, 14^{\circ}$ and $16^{\circ}$ were tested. The ground proximity was kept constant at $38 \mathrm{~mm}$, limited by the suspension geometry, as per $\mathrm{SAE}$ rules and guidelines. The inflation layers were introduced in the meshing to capture the details of the flow (Fig. 13). From the CFD analysis, a diffuser assembly with a $14^{\circ}$ upsweep angle produces the highest downforce and drag of $84.8 \mathrm{~N}$ and $115.6 \mathrm{~N}$ respectively. A model with the diffuser assembly and pressure streams are shown in Fig. 14.

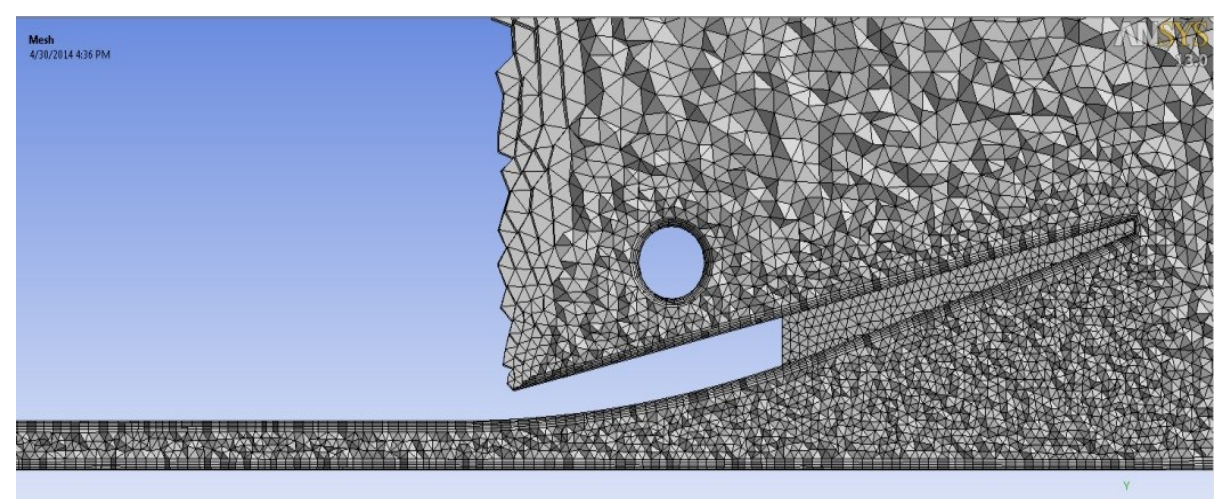

Fig. 13: Mesh generated across the diffuser. 


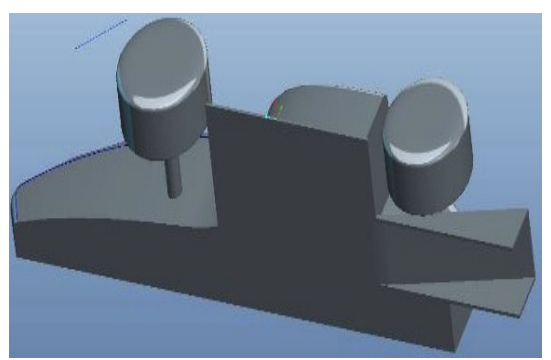

(a)

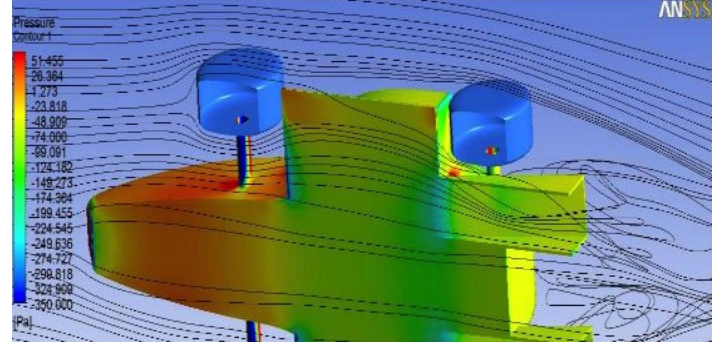

(b)

Fig. 14: (a) Diffuser assembly half model;

(b) streamlines and pressure contours across the diffuser.

\subsection{Complete Aerodynamic Package}

After analyzing every component individually, all the aerodynamic devices were then installed on the vehicle to measure the overall downforce and drag forces (Fig. 15). The overall drag and downforce generated by the integration of the complete aerodynamic package are $314.1 \mathrm{~N}$ and $634.9 \mathrm{~N}$ respectively. Velocity contours on split plane are shown in Fig. 16.

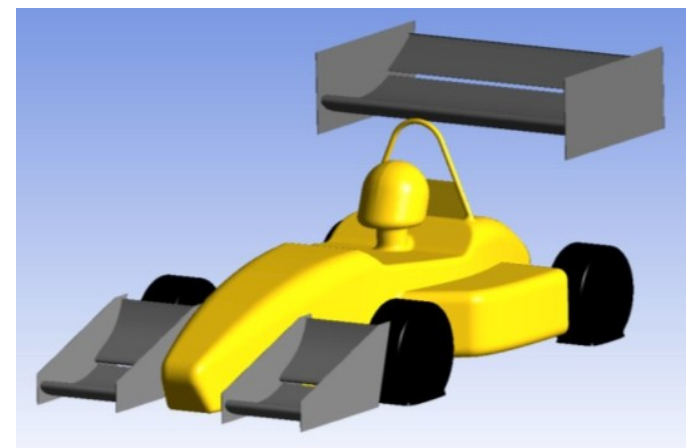

Fig. 15: Model of the race car with complete downforce package installed.

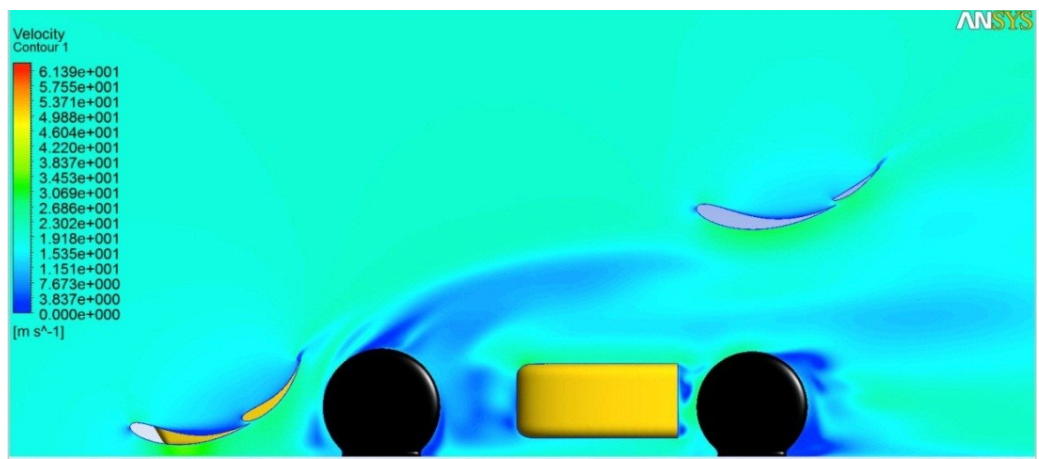

Fig. 16: Velocity contours on split plane.

\section{WIND TUNNEL}

In the late 1970s it was discovered that downforce can be created by means of ground effect. Therefore, it became essential to simulate the effect of the track on the car performance (on underbody, side pods, exposed wheels, wings). This meant that the moving belt approach is mandatory for vehicles with very low ground clearance (Formula 1 racing cars) or low drag coefficients (sports cars). The blockage ratio shouldn't exceed by 
$7.5 \%$ because there is a considerable distortion of the flow due to blockage and the effects created are complex to model [8-11]. Therefore scaling of the model was done so that the blockage ratio does not increase by $5 \%$ calculated using Eq. (1).

$$
\text { Blockage Ratio }=\frac{\text { Frontal area of Model }}{\text { Test section area } * \text { Scaling }}
$$

In a wind tunnel with a stationary ground plane a boundary layer build up on the "track" under the car, and can interfere with the boundary layer of the lower components of the car. Such a case cannot give the correct test results. Road effects produce much thinner boundary layer than the wind tunnel floor. There are several ways to remove the ground boundary layer, but the most effective method is to use a moving belt, with the wheels rotating with the belt. The simulation of rotating wheels could not be more effective. The importance of the exposed wheels in Indy and Formula 1 has been widely recognized, and neglecting this effect may have a large effect on the overall performances.

In order to maintain the flow quality inside the wind tunnel test section, fairings were introduced at the start and end of the moving ground platform. Therefore we came up with different wind tunnel testing setups in order to solve the problem created by boundary layer development across the vehicle.

\subsection{Test Setup}

In order to reduce the boundary layer thickness, the following wind tunnel arrangement with a moving belt and a platform raised to a height of $5 \mathrm{~cm}$ from ground was suggested. The vehicle was placed on a moving ground simulation with two setups (Fig. 17).

1. Vehicle was placed on a moving ground simulation which was placed on the wind tunnel floor. The road velocity was $11.2 \mathrm{~m} / \mathrm{s}$ and the boundary layer thickness at the estimated position of the vehicle was $2.6 \mathrm{~cm}$.

2. In order to reduce friction, vehicle was placed on a moving ground simulation, which was placed $5 \mathrm{c} \mathrm{m}$ above the wind tunnel floor. The boundary layer thickness at the estimated position of the vehicle was $1.8 \mathrm{~cm}$.

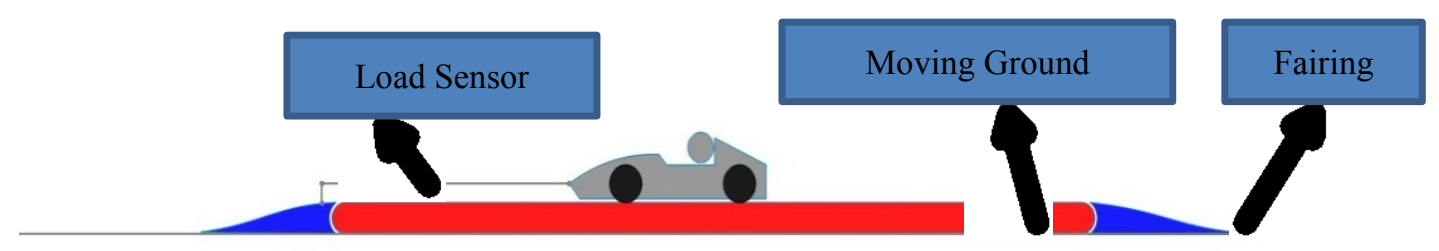

(a)

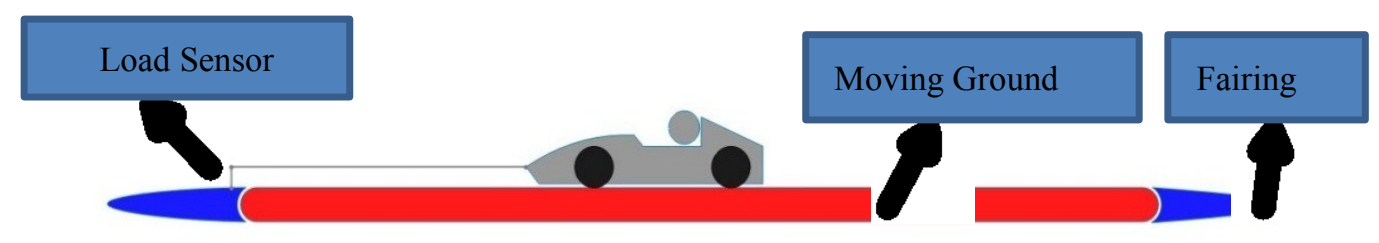

(b)

Fig. 17: Arrangement in wind tunnel test section; (a) setup 1, (b) setup 2. 
For setup 1 and setup 2, velocity streamlines in wind tunnel are shown in Fig. 18 and Fig. 19 respectively. Velocity profile for two marker points at $0.5 \mathrm{~m}$ and $1 \mathrm{~m}$ in the test section are plotted in Fig. 20 and Fig. 21 for setup 1 and setup 2 respectively. The maximum variation in velocity was observed: $17.1 \%$ and $10.7 \%$ for setup 1 and setup 2 respectively. Experimental setup for wind tunnel testing is shown in Fig. 22.

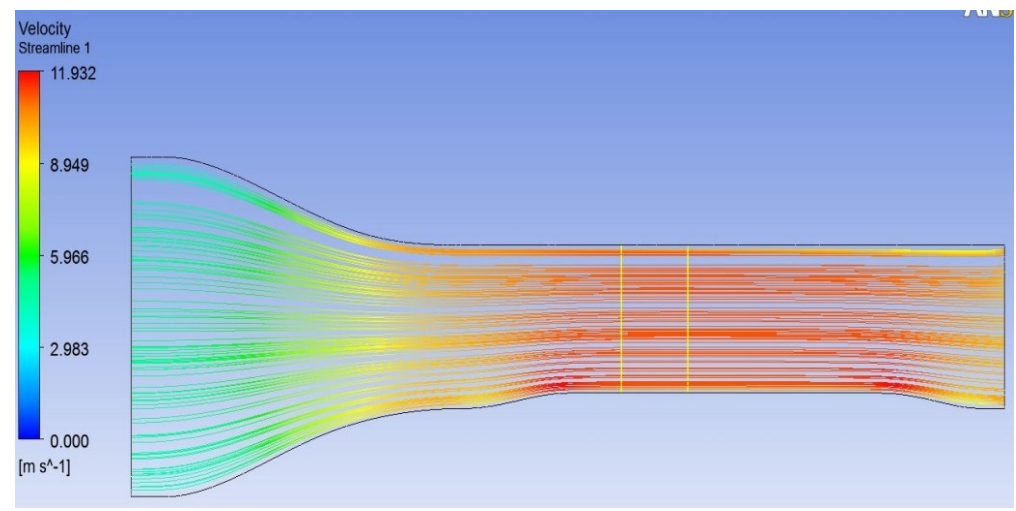

Fig. 18: Velocity streamlines in wind tunnel for setup 1.

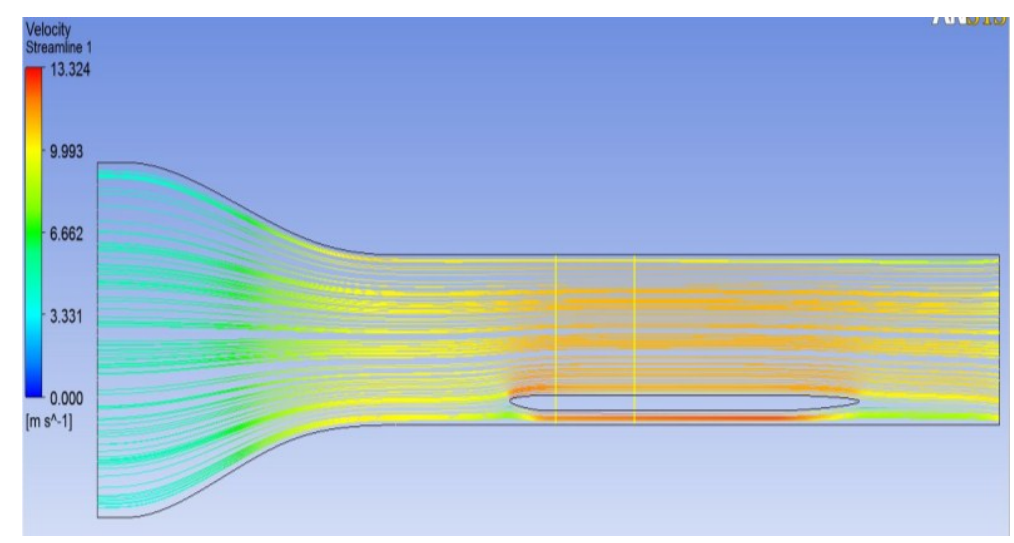

Fig. 19: Velocity streamlines in wind tunnel for setup 2.

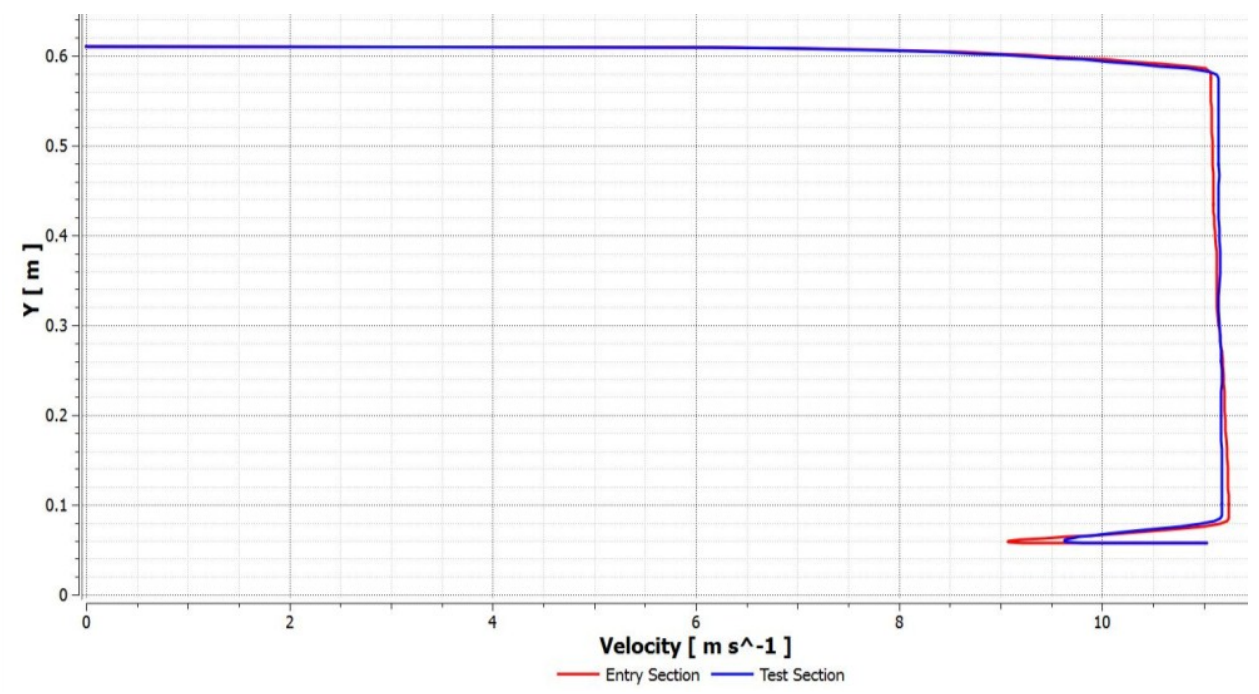

Fig. 20: Velocity profile in a wind tunnel test section for setup 1. 


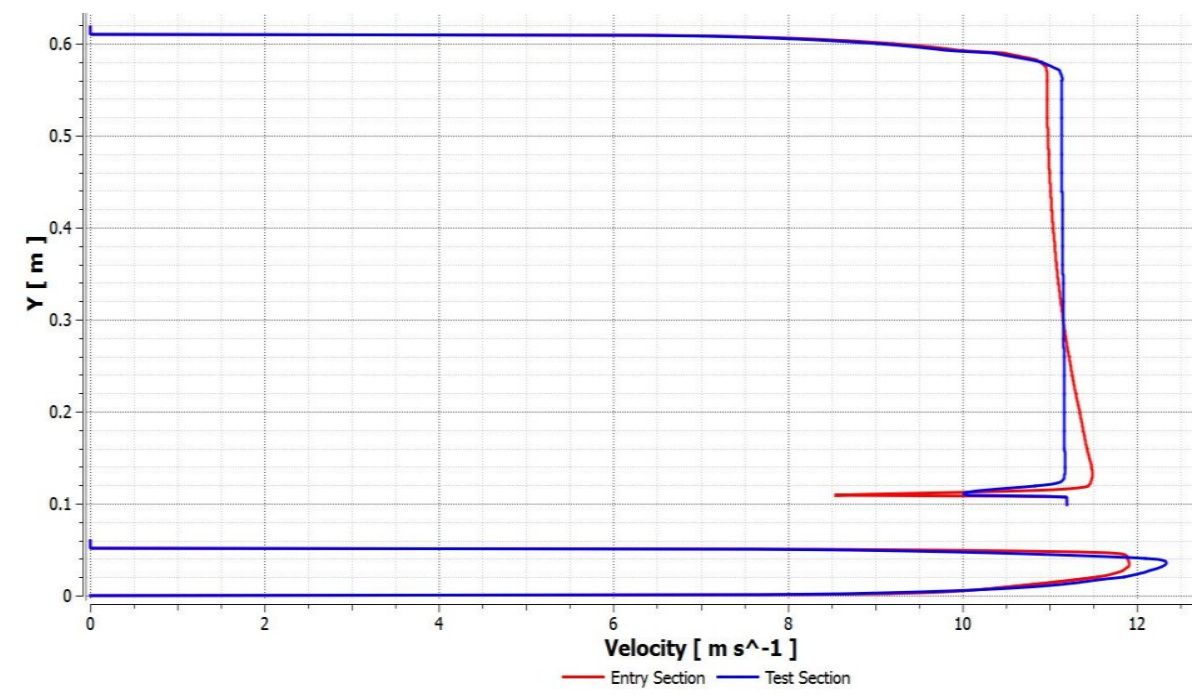

Fig. 21: Velocity profile in a wind tunnel test section for setup 2.

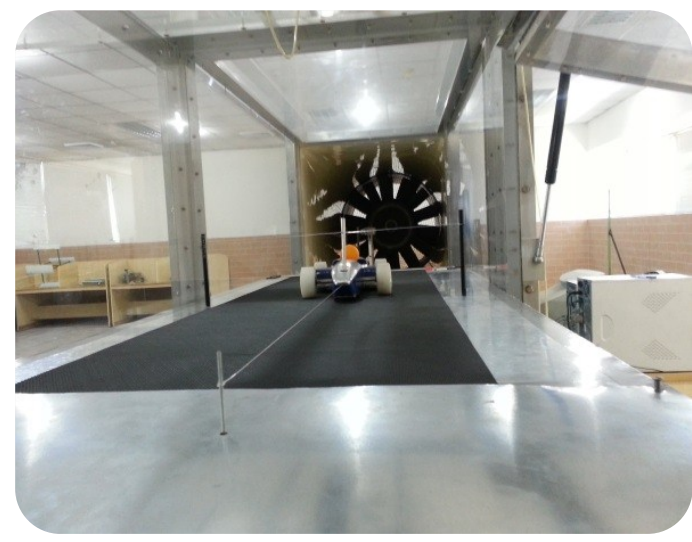

(a)

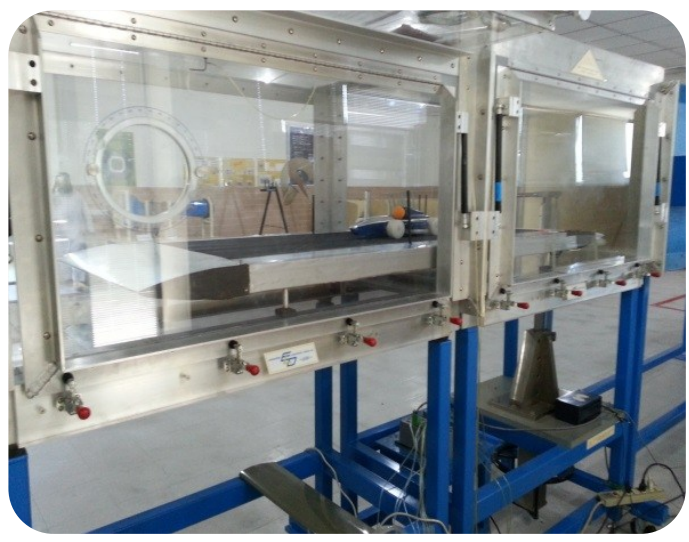

(b)

Fig. 22: Wind Tunnel used for experiments: (a) Test specimen view from inside; (b) Test specimen view from outside.

\subsection{Measurement of Forces}

With the model of the car mounted on a force balance (pole like supports usually three or five of them, two or four horizontal and one vertical), we can measure lift, drag, lateral forces, yaw, roll, and pitching moments over a range of angle of attack. This allows us to produce common aero curves such as lift coefficient versus angle of attack. Note that the force balance itself creates drag and potential turbulence that will affect the model and introduce errors into the measurements. The supporting structures are therefore smooth and teardrop shaped to minimize turbulence. A load sensor was connected to the front end of the test vehicle by the means of a fish wire. Whenever air swept across the vehicle it created a drag on the car, due to which the load sensor could measure the strain produced due to the deformation of the solid bar. This strain was then used to calculate the resulting drag force which was produced on the car.

All the results obtained are at a test section speed of $10 \mathrm{~m} / \mathrm{s}$. The drag force measured on the test vehicle using load sensor is $0.43 \mathrm{~N}$, hence coefficient of drag calculated using expression in equation 2 is $\left(C_{d}=0.57\right)$. From CFD simulation, coefficient of drag calculated 
is $C_{d}=0.63$. A difference of $9.5 \%$ between experimental and numerical results observed is within the acceptable range.

$$
C_{d}=\frac{2 D}{\rho V^{2} A}
$$

Table 2 shows comparison of numerical results for the various vehicle setups that were analyzed for the optimum performance of the vehicle.

Table 2: Comparison of various vehicles set up

\begin{tabular}{cccc}
\hline Sr. \# & Setup & Downforce (N) & Drag (N) \\
\hline 1 & Vehicle alone & 11.2 & 109.0 \\
2 & Vehicle with Diffuser & 84.8 & 115.6 \\
3 & Vehicle with Wings & 580.1 & 305.7 \\
4 & Full Downforce Package & 634.9 & 314.1 \\
\hline
\end{tabular}

\section{CONCLUSION}

Based on the detailed parametric numerical studies, it is concluded that with the addition of every downforce creating element, the total downforce is increased. Almost $60 \%$ of the downforce is created by the front and rear wings. Although according to the experts the diffuser creates $30 \%$ of the overall downforce; however in this study the difference is concluded due to some approximation in the diffuser modeling. Further improvements in diffuser section are possible and are recommended for future studies.

\section{REFERENCES}

[1] Lanfrit M. (2005) Best practice guidelines for handling Automotive External Aerodynamics with FLUENT. Fluent Deutschland GmbH Birkenweg Darmstadt/Germany. Version 1.2.

[2] Pro/Engineer. (2009) Wildfire Release 4.

[3] http://www.airfoiltools.com

[4] ANSYS CFX. (2009) Reference Guide. Release 11.

[5] Guilmineau E. (2008) Computational Study of Flow around a Simplified Car Body, Journal of Wind Engineering and Industrial Applications, 96:1207-1217.

[6] http://www.fsaesim.com

[7] Katz J. (1996) Race Car Aerodynamics: Designing for Speed (Engineering and Performance). Bentley Publishers; $2^{\text {nd }}$ edition. ISBN: 978-0837601427

[8] Minguez M, Pasquetti R, Serre E. (2008) High-Order Large Eddy Simulation of Flow Over the Ahmed Body Car Model. Physics of Fluids. Vol. 20, 095101/17.

[9] Bayraktar I, David L, Baysal O. (2001) Experimental and computational investigation of Ahmed body for ground vehicle aerodynamics, Technical University of Graz, SAE paper 2001-01-2742.

[10] Kapadia S, Roy S, Wurtzler K. (2003) Detached eddy simulation over a reference Ahmed car model, AIAA. Paper no. 2003-0857.

[11] Morel T. (1978) The effect of base slant on the flow pattern and drag of three-dimensional bodies with blunt ends, In: Sovran G, Morel T, Mason WT (Eds.) Aerodynamic drag mechanisms of bluff bodies and road vehicles. Plenum Press, New York, pp. 191-226. 